\title{
Ultraviolet radiation and health effects in the Antarctic
}

\author{
Desmond J. Lugg \& Colin R. Roy
}

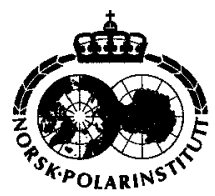

\begin{abstract}
With the recognition that global climate change may adversely affect human health, there has been an increase in relevant research worldwide. In the Antarctic medical research has been largely directed at the potential health effects of stratospheric ozone depletion. For over a decade continuous broad-band measurements of ultraviolet radiation (UVR) have been made at all Australian stations. Results of UV measurements are presented and comparisons made with the "ozone hole" moving over the stations, erythemal UVR increasing by a factor of more than 2.5 over a three day period. During late spring and despite the large difference in latitude, Davis, Antarctica, and Melbourne, Australia, are very similar in erythemal UVR. Antarctic immunological and photobiological research is presented and the role of UVR discussed. Epidemiological data is reviewed for short-term links between UVR and related disease. With increased awareness of the dangers of UVR and consequent changes in sun-related behaviour, the incidence of the acute effects of UVR is much lower than decades ago. As the itinerant Antarctic population spends a maximum of $12-18$ months at a time in that location it is an excellent control group for studies on the health effects of UVR on permanent populations at similar latitudes in the Arctic.
\end{abstract}

D. J. Lugg, Antarctic Division, Kingston, Tasmania, 7050 Australia; C. R. Roy, Australian Radiation Protection and Nuclear Safety Agency (ARPANSA), Yallambie, Victoria, 3085 Australia.

\section{Introduction}

With the recognition that global climate change may adversely affect human health (Haines 1991), there has been an increase in relevant research worldwide. Those living in the Antarctic regions are transient visitors, whose health is unlikely to be affected by regional temperature or precipitation changes due to global climate change. Some Antarctic medical research has been directed at determining the potential health effects of stratospheric ozone depletion, including assessment of the UVR environment to which humans are subjected. This is in accord with the Scientific Committee on Antarctic Research (SCAR) international plan for regional research on the role of the Antarctic in global change (SCAR 1993).

Health and the ozone layer came to the fore in the late 1980s (Mackie \& Rycroft 1998) with a number of workshops (SCOPE 1992; Acevedo \& Nolan 1993; IASC 1995) defining the current state of knowledge of the effects of UV-B radiation on humans - skin, eyes and the immune system.

Data are presented from the assessment of the ultraviolet radiation (UVR) environment at Australian National Antarctic Research Expeditions (ANARE) stations in the period 1988-1998, along with the results from a number of inter-related studies on immunology, virology, photobiology and epidemiology. Although not answering the health questions posed by ozone depletion, they add to the information available on human interaction with the Antarctic environment, especially with respect to UVR.

\section{Subjects}

Personnel on ANARE are volunteers, predominantly male, and mainly from temperate and subtropical areas. Those wintering spend from 12 to 
Antarctic ozone 1997

Davis and Casey Stations

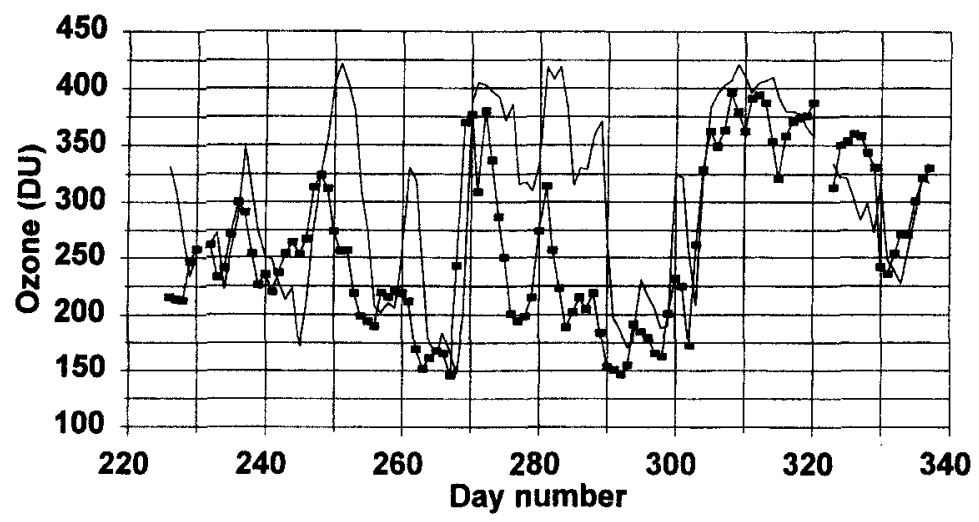

Fig. 1. Satellite ozone data for Davis and Casey Stations,

Antarctica, from mid-August to the end of November 1997.

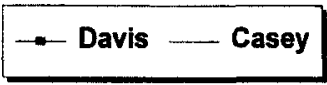

18 months continuously in Antarctica, while summer personnel may be in Antarctica from one to six months. Age range is from 18-64 (mean 35) years. All have passed a medical examination prior to going to Antarctica. The experimental protocols have been approved by Ethics Committees and all subjects have signed informed consent forms after the procedures have been explained to them.

\section{UVR environment}

In 1987 a UVR measurement programme was initiated by the Australian Radiation Laboratory (ARL), now Australian Radiation Protection and Nuclear Safety Agency (ARPANSA), and the Australian Antarctic Division. Since austral summer 1988-89, broad-band UVR measurements have been made at all ANARE continental stations, and in summer 1989-90 equipment was installed at Macquarie Island. Finance and personnel limited the initial programme which was later expanded by the installation of a spectroradiometer in summer 1993-94 at Davis. Roy, Gies, Tomlinson et al. (1994) have described the Antarctic network and some of the early results.

Total ozone is an important determinant of the amount of UV-B at the earth's surface. Large variations in ozone can result in very large fluctuations in UV-B. Figure 1 shows the satellite ozone data for Davis and Casey Stations for the period mid-August to the end of November 1997. Large variations occur over short time periods; around day 270 the ozone varied from 150 to $>400$ Dobson units (DU) in two days. In 1997 the "ozone hole" obviously has passed over several times during the period under review but this behaviour varies from year to year. The two stations respond in a similar pattern with Casey "lagging" by a few days, but the magnitude of change was often different as a result of the degree of cloud cover which in turn affects the surface UVR.

The effect of ozone changes is most obvious during clear sky days. Taking the large decrease in ozone at Casey around day 290 (Fig. 1) when two almost-clear days were measured, the erythemal UVR has increased by a factor of more than two and a half (Fig. 2). As the measurements were only one day apart, little of the depicted change can be attributed to the changing solar elevation.

The UVR has been expressed as a minimal erythemal dose (MED). As UV-B wavelengths are up to 1000 times as effective as UV-A wavelengths in producing biological effects (e.g. erythema), it is useful to take this into account when discussing UVR levels in terms of potential health effects. One MED is taken as being 
Fig. 2. The effect of ozone changes on clear sky erythemal UVR irradiance at Casey in October 1997. The UVR is expressed as minimal erythemal dose (MED).

\section{Erythemal UVR \\ Casey: October 1997}

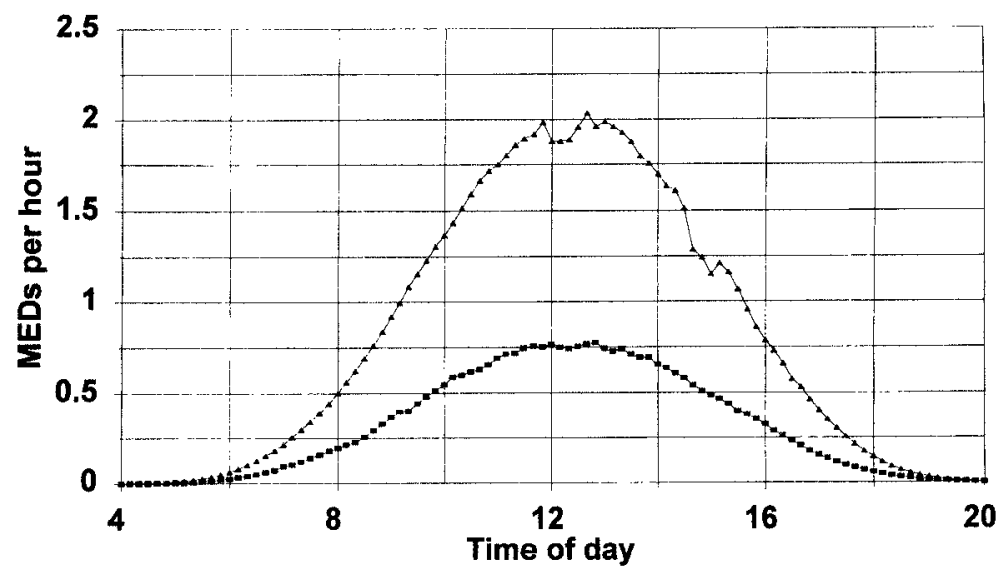

equivalent to $200 \mathrm{~J} / \mathrm{m}^{2}$ of effective UVR. The effective UVR is obtained by weighting the spectral UVR by the erythemal action spectra of the Commission Internationale d'Eclairage (CIE). This is presented in more detail in Roy, Gies \& Toomey (1995).

It should be noted that changes of the magnitude illustrated in Fig. 2 for clear skies are unknown outside Antarctica. A decrease in satellite ozone over Davis in clear skies in a five day period in late September to early October 1997 shows a similar response to Casey (Fig. 3). The Davis erythemal UVR is lower but the percentage change is greater.

UVR is very dependent on the solar elevation and hence latitude. This can be seen in Fig. 4 which shows the erythemal UVR over 1997 at Brisbane $\left(27.5^{\circ} \mathrm{S}\right)$, Melbourne $\left(37.8^{\circ} \mathrm{S}\right)$ and Davis Antarctica $\left(68.6^{\circ} \mathrm{S}\right)$. The measurements were made on cloud-free days spread throughout the year as indicated. Davis shows dramatically the effect of ozone depletion. During the late spring, and despite the large difference in latitude, Davis and Melbourne are very similar in erythemal UVR, although less than that of sub-tropical Brisbane.

\section{Epidemiology}

In assessing links between UVR and related disease, an accurate health register is needed to quantify the occurrence of ill-health in Antarctica; to compare incidence rates with different populations; to assess trends and to identify those at risk. The advent of the ANARE Health Register (King 1987; Sullivan et al. 1991) has laid the foundation for more accurate health data collection.

However, accurate data collection does not guarantee that one can quantify all the links between UVR and disease, as there is no general consensus on what are the major health consequences of UVR. Armstrong (1996) summarizes the major known or suspected health effects of solar UVR and the strength of evidence for those effects. Knowledge of a number of the effects has come from animal studies; there has been limited human research. However it is agreed that an increase in UVR is likely to result in harmful effects to humans.

The number of health events reported in the ANARE Health Register in the period 1987-1998 (2000 person years) that may be related to stratospheric ozone depletion and increased action of UVR include erythema (sunburn) 13 (rate 6.5/ 1000 person years); keratitis (snow blindness) 5 (2.5): pterygia 6 (3); cataract 2 with several further cases being diagnosed following return to Australia (1); skin cancer (malignant) 7 (3.5); viral disease (specifically herpes) 129 (64.5).

It is obvious from experience that more than 13 
Erythemal UVR

Davis Station: September/October 1997

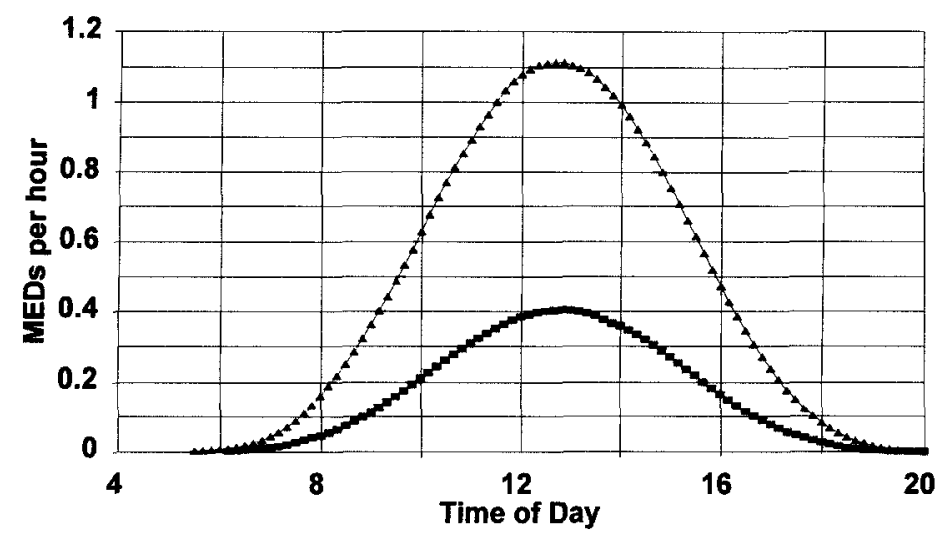

Fig. 3. The effect of ozone changes on clear sky erythemal UVR irradiance at Davis in September/October 1997. The UVR is expressed as minimal erythemal dose (MED). cases of sunburn occurred, but many were minor and not considered worth reporting to the doctor. With increased awareness of the dangers of UVR, and consequent change in sun-related behaviour including the use of clothing, sunglasses and sunscreens, the incidence of the acute effects of UVR is much lower now than decades ago. This is particularly true with regard to snow blindness.
It is doubtful if the cases of pterygia, cataract and skin cancer resulting from chronic UVR exposure can solely be related to the time the individuals spent in Antarctica. Armstrong (1996) considers that the evidence supporting the relation between UVR and cataracts and pterygia is weak. If cataracts and pterygia are UVR-related, exposure to UVR in Antarctica may only partially
Erythemal UVR 1997

\section{Brisbane, Melbourne and Davis}

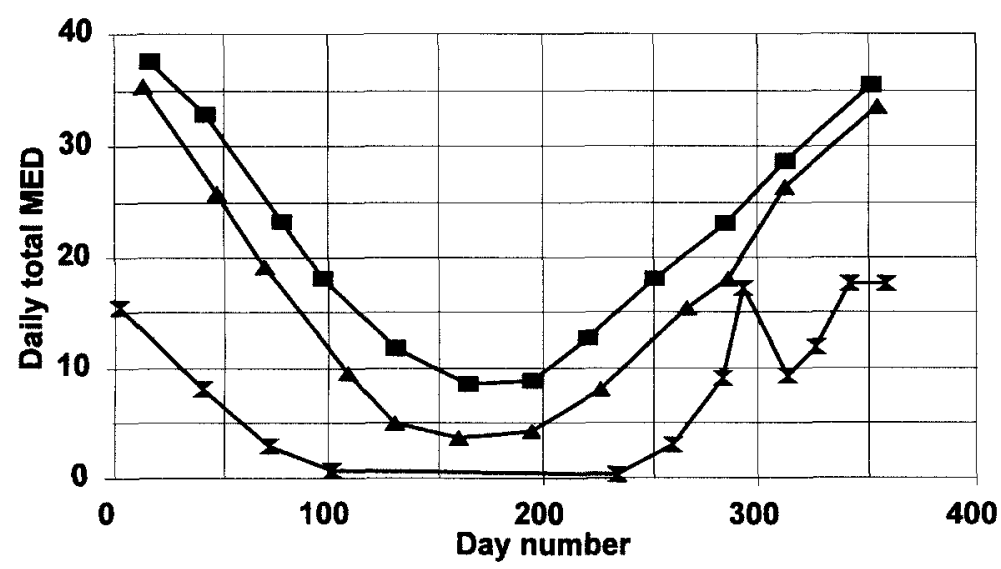

Fig. 4. A comparison of erythemal UVR throughout 1997 at Brisbane and Melbourne, Australia, and Davis, Antarctica.

\section{Brisbane $\left(27.5^{\circ} \mathrm{S}\right) \rightarrow$ Melbourne $\left(37.8^{\circ} \mathrm{S}\right) \rightarrow$ Davis $\left(68^{\circ} 6^{\circ} \mathrm{S}\right)$}


contribute to the disease, rather than being the sole cause. This can be said of other diseases associated with UVR exposure as well.

Of the seven malignant skin cancers one was a melanoma and six either basal cell or squamous cell carcinomas. Australians traditionally have a high exposure to UVR and a high rate of skin cancer (Giles \& Thursfield 1996). As Giles \& Thursfield have pointed out, non-melanocytic skin cancer (NMSC), although the most common cancer in Australia, is not routinely collected by cancer registeries, thus no comparative figures are available. Antarctic UVR may only be an added source to prior long-term Australian UVR exposure.

The number of cases of herpetic disease is of interest and will be discussed under immunology. Changes in immune responsiveness in Antarctica may be an additional possible effect of exposure to UVR, especially UV-B which has been shown to lead to suppression of immunological responses and to reactivate certain viruses which can exist in a latent form in humans (Acevedo \& Nolan 1993).

Reviewing the health effects of acute UVR in Antarctica suggests that stratospheric ozone depletion does not appear to have a major effect. With the hostile environment limiting skin exposure and people dressed in polar clothing, this lack of health effects is not surprising. The question of health effects of chronic exposure of the ANARE visitors to Antarctica may have to wait until the study currently being undertaken by P. Sullivan on the long-term effects of wintering in Antarctica is concluded. However, as Armstrong (1996: 154) has pointed out, identifying the increased health risks resulting from increases in ambient UVR must be "based on analysis of the way in which incidence varies geographically with changing ambient UV." This involves estimating amplification factors, assuming adaptive responses remain constant, and taking into account sun-related behavioural and local environmental changes together with trends in detection, diagnosis and recording.

\section{Immunological studies}

In 1984 cell mediated immunity (CMI) was assessed at quarterly intervals at Mawson and Macquarie Island (Williams et al. 1986). While the response of the Macquarie Island group was similar to healthy, normal populations, the Mawson group showed decreased cutaneous responses with significant anergy (a state of diminished or absent CMI as shown by the inability to react to a battery of common skin test antigens) and hypoergy. An explanation for the Mawson group findings as opposed to those from Macquarie Island was that cold, total isolation, reduced environmental immunological triggers, psychological and other stressors on ANARE personnel caused a diminished immune function.

The 1984 study was repeated on a further ten Antarctic and sub-Antarctic wintering groups over the period 1986-92. Two hundred and twenty five expedition personnel volunteered for this study. The results (Muller et al. 1995) paralleled the original study and showed that while the Macquarie Island populations had levels of responsiveness and hypoergy (9\%), comparable to healthy populations in temperate zones, the Antarctic continental groups showed levels of hypoergy of $36 \%$. There was no seasonal variation in the pattern of decreased immunological responsiveness, but it was pointed out that with the lowered immunity in Antarctica, where medical care is limited, there may be health implications.

Immune function is modulated by a complex set of neuroendocrine factors including sex hormones, vitamin D metabolites and stress. Studies have also shown a reduction in testosterone levels in wintering ANARE expeditioners and suggested a correlation between levels of anxiety and reduced immune function in brief trip expeditioners. Nineteen male Antarctic expeditioners were followed by three monthly assessments of cell mediated immunity, levels of testosterone and vitamin D metabolite and psychological indicators of anxiety (Pitson, Lugg \& Muller 1996). There was a significant reduction in immune function during the study period, consistent with previous Antarctic studies. Levels of testosterone, anxiety and the immunoregulatory metabolite of vitamin D did not alter significantly. In this group the reduction in immune function did not show a correlation with levels of anxiety or the hormones studied.

At Casey in 1993, Tingate et al. (1997) found alterations of $\mathrm{T}$ cell function, including depression of CMI responses and a peak $50 \%$ reduction of $\mathrm{T}$ cell proliferation to the mitogen phytohaemogglutinin (PHA). T cell dysfunction was mediated by changes within the peripheral blood mononuclear cell (PBMC) compartment, including a paradoxi- 
cal atypical monocytosis associated with altered production of inflammatory cytokines (a reduction in TNF- $\infty$ and changes in IL-1, IL-2, IL-6, IL-1ra and IL-10). Antarctic isolation was associated with altered latent herpesvirus homeostasis, including increased herpesvirus shedding and expansion of the polyclonal latent Epstein-Barr virus infected B cell populations. Two subsequent groups from Davis and Mawson, both of whom exhibited depressed CMI responses, also showed an increase in Epstein-Barr virus reactivation early during winter over. Viral shedding was more frequent during the anergic or hypoergic state for most subjects (Mehta et al. 1998).

Although no diseases could be associated with the immune changes, the findings have important long-term health implications for those isolated in harsh environments. The large number of cases of herpetic disease reviewed under epidemiology are probably linked to the immune depression, which in turn is linked to increased viral shedding. What role does UVR have on the altered immune status in Antarctica?

\section{Photobiology}

Findings of suppression of the human immune system by UV-B and suggestions that immune suppression by UV-B may be modulated by urocanic acid in mammalian skin led to Aldous and DeLeacey (Lugg 1994) studying the relationship of cis and trans urocanic acid in skin from March to November in Antarctica. There was a winter drop of urocanic acid and a spring rise of the cis to trans ratio. Comparisons with a control group in Adelaide, South Australia, showed that the results for spring in Antarctica were greater than those in Adelaide. Correlation of the urocanic acid levels with UV-B was not possible as the UV$B$ measuring system was not in place at that time. This research led to the initiation of the ARL/ Antarctic Division monitoring of UVR in Antarctica, thus enabling the effect of seasonal radiation fluctuations on humans in Antarctica to be monitored.

One such study at Davis in 1991 studied the effect of seasonal UVR fluctuations on vitamin D homeostasis (Pitson, Lugg \& Roy 1996). Vitamin $\mathrm{D}$ and its metabolites are important in bone and calcium metabolism. Vitamin D is derived from both the skin (vitamin D3) and food (vitamin D2 and some vitamin D3). The major source of vitamin $\mathrm{D}$ in a healthy population has been shown to be sunlight (Stamp \& Round 1974; Chesney et al. 1981). Despite the dramatic changes in UV-B levels and subsequent changes in 25-hydroxyvitamin $\mathrm{D}$ concentration during the Antarctic year, active metabolite 1, 25-dihydroxyvitamin D homeostasis would seem to be maintained. This means that, providing individuals with pre-existing vitamin D deficiencies are detected before departure for Antarctica and missions are limited in duration, clinical deficiency is unlikely to occur as a result of the lack of UV-B in the mid-winter period.

\section{Synthesis}

Assessment of the UVR environment at ANARE stations on the Antarctic Continent over a number of years as described above shows that austral winter readings are, as expected, minimal, while during the spring and early summer dramatic changes occur and the effect of ozone depletion is obvious. However during the late spring and despite the large difference in latitude Davis and Melbourne (temperate) are very similar in erythemal UVR, although less than sub-tropical Brisbane. Erythemal UVR changes in Antarctica show increases of up to two and a half times in very short periods; changes of this magnitude (for clear skies) are unknown outside Antarctica.

Acute effects of UVR in the form of sunburn and snow blindness are seen but the incidence is very low. From the ANARE epidemiological data available it is not possible to quantify health changes due to chronic UVR. A high rate of disease has occurred in the same wintering groups at ANARE stations who had repeated research findings of lowered immunity and altered latent herpesvirus homeostasis including increased herpesvirus shedding. It has not been possible to correlate this with UVR but further research would appear justified to assess the role of UV-B, urocanic acid and immune changes in these populations, arguably the most isolated on Earth. Research as described above has shown that UVR in Antarctica where there is deprivation of sun exposure, is important in the production of vitamin $D$; the only certain beneficial effect of UVR.

Conference and workshop proceedings have been particularly important in focusing on research 
needed to answer questions concerning the impact of increased solar UV-B radiation on the biosphere. In assessing the health effects of ozone depletion it is important to review the incidences of UV-related disease in different latitudes as well as to compare latitudes in different hemispheres. Comparisons between north and south polar regions may be valuable for future management and it is hoped this symposium will become a catalyst for such action.

Acknowledgements. - The assistance of the Antarctic medical practitioners and physicists in collecting the field data, David Tomlinson and Simon Toomey at Australian Radiation Laboratories, and Dr Peter Sullivan and Robin Taylor at Antarctic Division is gratefully acknowledged.

\section{References}

Acevedo, J. \& Nolan, C. (eds.) 1993: Environmental UV radiation-causes, effects, consequences. Brussels: Commission of the European Communities Directorate-General XII for Science, Research and Development.

Armstrong, B. 1996: An overview. Cancer Forum 20(3), 152-157.

Chesney, R. W., Rosen, J. F., Hamstra, A. I., Smith, C., Mahaffey, K. \& DeLuca, H. F. 1981: Absence of seasonal variation in serum concentration of 1,25 -dihydroxyvitamin $D$ despite a rise in 25 -hydroxy vitamin $\mathrm{D}$ in summer. $J$. Clin. Endocrinol. Metab. 53, 139-142.

Giles, G. \& Thursfield, V. 1996: Trends in skin cancer in Australia. Cancer Forum 20(3), 188-191.

Haines, A. 1991: Global warming and health. Br. Med. J. 302, 669-670.

IASC (International Arctic Science Committee) 1995: Effects of increased ultraviolet radiation in the Arctic. IASC Report No. 2. Oslo: IASC.

King, H. 1987: A new health register for Australian National Antarctic Research Expeditions. Polar Rec. 23, 719-720.

Lugg, D. J. 1994: Human interaction with the Antarctic environment: studies in immunology, photobiology and epidemiology. Arct. Med. Res. 53(2), 407-409.
Mackie, R. M. \& Rycroft, M. J. 1988: Health and the ozone layer. Br. Med. J. 297, 369-370.

Mehta, S. K., Pierson, D. L., Cooley, H. N., Dubow, R. J. \& Lugg, D. J. 1998: Epstein-Barr virus shedding in Antarctic winter-over teams. Abstracts of the American Society Microbiology Meeting, Atlanta, USA, 17-21 May 1998, p. 488. Washington D.C.: American Society of Microbiology.

Muller, H. K., Lugg D. J. \& Quinn, D. 1995: Cell mediated immunity in Antarctic wintering personnel; 1984-1992. Immunol. Cell Biol. 73, 316-320.

Pitson, G. A., Lugg, D. J. \& Muller, H. K. 1996: Seasonal cutaneous immune responses in an Antarctic wintering group: no association with testosterone, vitamin D metabolites, or anxiety score. Arct. Med. Res. 55, 118-122.

Pitson, G. A., Lugg, D. J. \& Roy, C. R. 1996: Effect of seasonal ultraviolet radiation fluctuations on Vitamin $D$ homeostasis in Antarctic expeditioners. Eur. J. Appl. Physiol. 72, 231-234.

Roy, C. R., Gies, H. P., Tomlinson, D. W. \& Lugg, D. J. 1994: Effects of ozone depletion on the ultraviolet radiation environment at the Australian stations in Antarctica. In P. Penhale \& C. S. Weiler (eds): Ultraviolet radiation in Antarctica: measurements and biological effects. Pp. 1-15. Washington: American Geophysical Union.

Roy, C. R., Gies, H. P. \& Toomey, S. 1995: The solar UV radiation environment: measurement techniques and results. J. Photochem. Photobiol. B: Biol. 31, 21-27.

SCAR (Scientific Committee on Antarctic Research) 1993: The role of the Antarctic in global change - an international plan for a regional research program. Cambridge: SCAR.

SCOPE (Scientific Committee on Problems of the Environment) 1992: Effects of increased ultraviolet radiation on biological systems. Paris: SCOPE.

Stamp, T. C. B. \& Round, J. M. 1974: Seasonal changes in human plasma levels of 25-hydroxyvitamin D. Nature 247 , 563-565.

Sullivan P., Gormly, P. J., Lugg, D. J. \& Watts, D. J. 1991: The Australian National Antarctic Research Expeditions Health Register: three years of operation. In B. Postl et al. (eds): Circumpolar health 90. Pp. 502-504. Winnipeg: University of Manitoba Press.

Tingate, T. R., Lugg, D. J., Muller, H. K., Stowe, R. T. \& Pierson, D. L. 1997: Antarctic isolation: immune and viral studies. Immunol. Cell Biol. 75, 275-283.

Williams, D. L., Climie, A., Muller, H. K. \& Lugg, D. J. 1986: Cell mediated immunity in healthy adults in Antarctica and the sub-Antarctic. J. Clin. Lab. Immunol. 20, 43-49. 